\title{
Genetic and genomic dissection of dry matter intake at different lactation stages in primiparous Holstein cows
}

\author{
J. Tetens, ${ }^{1}$ G. Thaller, and N. Krattenmacher ${ }^{1,2}$ \\ Institute of Animal Breeding and Husbandry, Christian-Albrechts-University, D-24118 Kiel, Germany
}

\begin{abstract}
Dry matter intake (DMI) and feed efficiency are economically relevant traits. Simultaneous selection for low DMI and high milk yield might improve feed efficiency, but bears the risk of aggravating the negative energy balance and related health problems in early lactation. Lactation stage-specific selection might provide a possibility to optimize the trajectory of DMI across days in milk (DIM), but requires in-depth knowledge about genetic parameters within and across lactation stages. Within the current study, daily heritabilities and genetic correlations between DMI records from different lactation stages were estimated using random regression models based on 910 primiparous Holstein cows. The heritability estimates from DIM 11 to 180 follow a slightly parabolic curve varying from 0.26 (DIM 121) to 0.37 (DIM 11 and 180). Genetic correlations estimated between DIM 11, 30, 80, 130, and 180 were all positive, ranging from 0.29 (DIM 11 and 180) to 0.97 (DIM 11 and 30; i.e., the correlations are inversely related to the length of the interval between compared DIM). Deregressed estimated breeding values for the same lactation days were used as phenotypes in sequential genomewide association studies using 681 cows drawn from the study population and genotyped for the Illumina SNP50 BeadChip (Illumina Inc., San Diego, CA). A total of 21 SNP on 10 chromosomes exceeded the chromosomewise significance threshold for at least 1 analyzed DIM, pointing to some interesting candidate genes directly involved in the regulation of feed intake. Association signals were restricted to certain lactation stages, thus supporting the genetic correlations. Partitioning the explained variance onto chromosomes revealed a large contribution of Bos taurus autosome 7 not harboring any associated marker in the current study. The results contribute to the knowledge about the genetic architecture of the complex phenotype DMI and might provide valuable information for future selection efforts.
\end{abstract}

Received July 26, 2013.

Accepted September 23, 2013.

${ }^{1}$ These authors contributed equally to the work.

${ }^{2}$ Corresponding author: nbuttchereit@tierzucht.uni-kiel.de
Key words: dairy cow, dry matter intake, genetic parameters, genome-wide association study

\section{INTRODUCTION}

Dry matter intake is a trait of interest for dairy cattle breeding. Feed is a major component of the milk production costs and, therefore, it appears possible to improve economic efficiency by selecting for DMI. However, there has been a long-running debate whether and how DMI should be included in breeding programs (Van Arendonk et al., 1991; de Haas et al., 2012; Veerkamp et al., 2012; Berry and Crowley, 2013). This is a complicated task, as recording of DMI is difficult and expensive. Data are almost exclusively recorded in research herds, resulting in a small number of records (Vallimont et al., 2010) and a lack of reliable genetic parameters (Veerkamp et al., 2012). Another reason why an inclusion of DMI in breeding programs is not trivial is that the feed eaten by a cow is used for several other functions than milk production, such as maintenance, growth, and reproduction (Veerkamp, 1998). A reduction of DMI in early lactation leads to a more pronounced energy deficit postpartum (Spurlock et al., 2012). This, in turn, affects the constitution of the cow (Collard et al., 2000) and causes metabolic stress (Pryce and Løvendahl, 1999). Cows in a prolonged negative energy balance often fail to maintain functional fitness and, thus, the majority of metabolic and infectious diseases occur during early lactation (Goff and Horst, 1997). These diseases result in reduced milk yield, extra costs for drugs and veterinary treatments, additional labor, and involuntary culling and, thereby, cause economic loss (Heringstad et al., 2000). Moreover, several studies reported negative effects of an energy deficit on the reproductive performance of dairy cows (e.g., Reist et al., 2003), which is another limiting factor for profitability of milk production. Thus, breeding for economic efficiency of dairy cattle is difficult and requires in-depth knowledge of DMI genetics and genomics.

Published heritability estimates for DMI range from 0.04 to 0.54 (Veerkamp and Thompson, 1999; Coffey et al., 2001; Hüttmann et al., 2009; Buttchereit et al., 
2011; Spurlock et al., 2012). Heritability of DMI is shown to vary across lactation, but uncertainty exists about the trajectory. The same applies to the genetic correlations between DMI observations across lactation. Several authors found low (Veerkamp and Thompson, 1999; Berry et al., 2007; Hüttmann et al., 2009) to negative (Koenen and Veerkamp, 1998; Coffey et al., 2001; Buttchereit et al., 2011) correlations between DMI measurements from early and mid lactation, whereas Spurlock et al. (2012) reported that genetic correlations between DMI in early and mid lactation remained above 0.70. In addition, Coffey et al. (2001) found highly positive correlations between DMI records from early and late lactation, which was in contrast to the results of Berry et al. (2007). Those authors, studying the first 305 DIM, observed the weakest genetic correlation between DMI at 8 DIM and 305 DIM. Most estimates for genetic correlations, however, originate from small data sets and either no standard errors were provided or the majority of the genetic correlations was not significantly different from zero $(P>0.05)$ because of large standard errors. Therefore, there is a lack of reliable estimates, leading to several gaps in knowledge. For example, it is unknown whether selection for efficient cows with a low DMI in mid or late lactation would have implications on early lactation DMI. A reduction in DMI during the initial lactation period could have severe consequences on fertility and health due to the detrimental effects of a pronounced energy deficit. Thus, the use of an inclusion of DMI in breeding goals depends strongly on genetic interrelationships across lactation. In this context, it is quite interesting that results from previous studies indicate that DMI might be influenced by different genes at different stages of lactation (Koenen and Veerkamp, 1998; Berry et al., 2007). Recently, Veerkamp et al. (2012) performed a genome-wide association study (GWAS) for DMI and identified potential candidate genes. The average DMI for wk 3 to 15 of lactation was used as phenotype in their study. However, if DMI is controlled by different genes at different lactation stages, GWAS for DMI at different DIM are needed to gain a better insight into the genetic architecture of this trait.

The objectives of the current study were to quantify the degree and change in heritability of DMI across lactation and to estimate genetic correlations between DMI records from different DIM. Furthermore, deregressed EBV for DMI were estimated using random regression methodology and the results for DIM 11, 30, 80, 130, and 180 were used as phenotypes for GWAS, with the aim of identifying genomic regions significantly associated with DMI at specific or multiple stages of lactation. The study was limited to first lactation, with emphasis on early and mid lactation.

\section{MATERIALS AND METHODS}

Data from primiparous Holstein Friesian cows were recorded between September 2005 and December 2012 on the dairy research farm Karkendamm of the Institute of Animal Breeding and Husbandry, ChristianAlbrechts-University (Kiel, Germany). This farm runs a bull dam performance test and all Karkendamm bull dam candidates had to complete a test period under commercial conditions in a freestall barn until DIM 180. Nonqualified primiparous cows left the herd afterward. Therefore, only records between DIM 11 (start of feed intake recording) and DIM 180 were used in the present investigation.

Cows were milked twice per day and fed a TMR diet ad libitum. Daily TMR intake was recorded for each animal via single feeding troughs equipped with a weighing unit and automatic cow identification. As cows were generally housed separately during the first 10 DIM, no feed intake data were available for this period. Individual TMR intake was deleted for the first and last day with TMR intake information and if cows were separated for insemination or pregnancy testing. Values obtained for fresh TMR intake were discarded if they were among the $0.5 \%$ highest or $0.5 \%$ lowest values, resulting in a range of fresh TMR intake between 4.8 and $77.3 \mathrm{~kg}$. Dry matter content of the TMR was analyzed twice weekly. The average $\mathrm{NE}_{\mathrm{L}}$ of the TMR was $7.1 \mathrm{MJ} / \mathrm{kg}$ of DM. Fixed amounts of concentrates were dispensed via concentrate feeders. Primiparous cows in the first 180 DIM consumed an average of 2.26 $\mathrm{kg}$ of concentrate DM per day $(\mathrm{SD}=0.49 \mathrm{~kg}$ of $\mathrm{DM} / \mathrm{d})$. Total mixed ration DM intake was $17.88 \mathrm{~kg} / \mathrm{d}$, on average $(\mathrm{SD}=4.79 \mathrm{~kg}$ of $\mathrm{DM} / \mathrm{d})$.

Animals were excluded from all further analyses if the number of DMI observations per cow across the entire period was less than 4 . This resulted in 910 primiparous cows and an average number of 103 DMI observations per cow (93,797 DMI observations, in total). The maximum number of DMI observations per cow was 165. The total DMI (concentrate and TMR intake) in this data set was $20.17 \mathrm{~kg} / \mathrm{d}$, on average, and ranged between 1.99 and $45.45 \mathrm{~kg} / \mathrm{d}$.

By tracing the pedigree of cows with observations 3 generations back, a pedigree file consisting of 5,683 animals was created. Data were analyzed using a random regression animal model considering the fixed effects test day, age at first calving, and stage of lactation. Age at first calving was divided into 5 classes (21 to $25,26,27,28$, and 29 to $38 \mathrm{mo}$ ). The general lactation curve was modeled by the function according to Ali and Schaeffer (1987), and random regression coefficients for permanent and additive genetic effects were modeled applying Legendre polynomials of 2 degrees: 
Table 1. Descriptive statistics of the deregressed EBV

\begin{tabular}{lcccc}
\hline Trait $^{1}$ & Mean & SD & Minimum & Maximum \\
\hline DMI11 & 0.23 & 3.23 & -12.55 & 10.68 \\
DMI30 & 0.20 & 2.90 & -12.72 & 09.63 \\
DMI80 & 0.19 & 2.72 & -14.38 & 08.72 \\
DMI130 & 0.28 & 2.87 & -15.66 & 12.32 \\
DMI180 & 0.48 & 3.39 & -16.58 & 16.34 \\
\hline
\end{tabular}

${ }^{1}$ Deregressed EBV for DMI at DIM 11, 30, 80, 130, and 180.

$$
\begin{aligned}
& y_{i j k l m}=T D_{i}+A F C_{i}+\sum_{n=1}^{4} b_{n} x_{i j k l m n}(d)+\sum_{n=0}^{2} p_{k n} x_{i j k l m n}(d) \\
& +\sum_{n=0}^{2} a_{l n} x_{i j k l m n}(d)+e_{i j k l m},
\end{aligned}
$$

where $y_{i j k l m}$ is the $m$ th observation of DMI; $T D_{i}$ represents the fixed effect of the test day $i(i=1$ to 2,023$)$; $A F C_{j}$ is the fixed effect of age at first calving ( $j=1$ to 5 ); $b_{n}$ are the fixed regression coefficients on lactation day $d$, with $x_{i j k l m 1}(d)=d / 190, x_{i j k l m 2}(d)=(d / 190)^{2}, x_{i j k l m 3}(d)$ $=\ln (190 / d)$, and $x_{i j k l m 4}(d)=[\ln (190 / d)]^{2} ; p_{k}$ represents the random regression coefficients for the permanent environmental effect of the $k$ th animal with phenotypic records; $a_{l}$ are the random regression coefficients for the additive genetic effect of animal $l$ in the pedigree with $x_{i j k l m 0}(d)=1, x_{i j k l m 1}(d)=-1+2(\mathrm{~d}-11 / 180-11)$, and $x_{i j k l m 2}(d)=0.5\left\{3[-1+2(\mathrm{~d}-11 / 180-11)]^{2}-1\right\}$ ( $k=1$ to $910 ; l=1$ to 5,683$)$; and $e_{i j k l m}$ is the random error term.

Residual errors were expected to have heterogeneous variances, so the first 180 DIM were split into 6 measurement error classes (11 to 30,31 to 60,61 to 90 , 91 to 120,121 to 150 , and 151 to 180 DIM). Within these classes, residual errors were assumed to be homogeneous. Residual covariances were assumed to be zero.

Variance components and EBV for DMI were estimated via ASReml 3.0 software (Gilmour et al., 2009). Standard errors for heritability estimates and genetic correlations between daily DMI measurements across lactation were calculated with the method proposed by Fischer et al. (2004).

For the GWAS, the daily EBV for DIM 11, 30, 80, 130 , and 180 from cows with at least 4 DMI observations were used as phenotypes. These EBV were deregressed by dividing the EBV by their respective reliabilities. A summary of the deregressed EBV is given in Table 1.

\section{Genotyping}

A total of 681 animals with phenotypic information were genotyped using the Illumina SNP50v1 BeadChip (Illumina Inc., San Diego, CA) comprising a total of 54,001 SNP markers. The amount of missing genotypes per individual was below $1 \%$, on average, and no ani- mal had to be removed due to poor genotyping quality. Loci with $>10 \%$ missing genotypes, a minor allele frequency $<0.05$, or unknown genomic position based on the bovine genome assembly UMD3.1 (http://www. bovinegenome.org/cgi-bin/gbrowse/bovine_UMD31/) were excluded, resulting in a final set of 40,407 informative markers. Quality control and data preparation were done with the PLINK package (Purcell et al., 2007).

\section{GWAS}

Genome-wide association studies were carried out applying a linear mixed model approach implemented in the package GEMMA (genome-wide mixed-model association; Zhou and Stephens, 2012). For each marker, GEMMA fits the following mixed model:

$$
\mathbf{y}=\mathbf{W} \boldsymbol{\alpha}+\mathbf{X} \beta+\mathbf{u}+\varepsilon
$$

where $\mathbf{y}$ is an $n \times 1$ vector of deregressed EBV for $n$ cows, $\mathbf{W}$ is an $n \times c$ incidence matrix of covariates including only the intercept here, $\boldsymbol{\alpha}$ is a vector of corresponding coefficients including the intercept, $\mathbf{X}$ represents an $n \times 1$ vector of marker genotypes at the locus tested and $\beta$ the corresponding effect size, and $\mathbf{u}$ is a vector of random genetic effects, with $\mathbf{u} \sim N\left(0, \mathbf{A} \sigma_{g}^{2}\right)$, where $\sigma_{g}^{2}$ represents the genetic variance and $\mathbf{A}$ is the relationship matrix, respectively. Here, the genomic relationship matrix (GRM) calculated with the GCTA (genome-wide complex trait analysis) software package according to Yang et al. (2011) was used. Finally, $\varepsilon$ is a random residual term, with $\varepsilon \sim N\left(0, \mathbf{I} \sigma_{\varepsilon}^{2}\right)$, where $\sigma_{\varepsilon}^{2}$ represents the residual variance and $\mathbf{I}$ represents an identity matrix. The alternative hypothesis of $\mathrm{H}_{1}: \beta \neq 0$ was tested against the null hypothesis $\mathrm{H}_{0}: \beta=0$ using the Wald test.

To account for multiple testing, the modified Bonferroni approach (simple $M$ ) of Gao et al. (2008) was applied. Briefly, the procedure accounts for the fact that association tests in GWAS are not independent due to linkage disequilibrium between markers. Using a principal components approach applied to a pairwise marker correlation matrix, the number of effective tests to be used in subsequent Bonferroni correction is estimated. 
The approach has been shown to be comparable to permutation-based methods in terms of efficiency and accuracy, but is computationally less demanding (Gao et al., 2008, 2010). The numbers of effective markers were estimated chromosome-wise and summed to assess genome-wide significance level.

\section{ANOVA Explained by Markers}

For each of the 5 analyzed DIM, the proportion of deregressed EBV variance (in this context further referred to as phenotypic variance) explained by all SNP was estimated and the variance was partitioned onto chromosomes using the GCTA package (Yang et al., 2011). A GRM based on all SNP as well as GRM based on the SNP of each chromosome, respectively, were built using the formula implemented in the GCTA software, where the genetic relationship between animals $j$ and $k\left(A_{j k}\right)$ is calculated as follows:

$$
A_{j k}=\frac{1}{N} \sum_{i=1}^{N} \frac{\left(x_{i j}-2 p_{i}\right)\left(x_{i k}-2 p_{i}\right)}{2 p_{i}\left(1-p_{i}\right)},
$$

where $N$ is the number of SNP; $x_{i j}$ and $x_{i k}$ represent the number of reference alleles at SNP locus $i$ for animals $j$ and $k$, respectively; and $p_{i}$ is the allele frequency of the respective allele at this marker locus.

Variance components were estimated using the GCTA command -reml, fitting a mixed linear model of the form

$$
\mathbf{y}=\mathbf{X} \boldsymbol{\beta}+\sum_{i=1}^{r} \mathbf{g}_{i}+\varepsilon \text { with } \operatorname{var}(\mathbf{y})=\sum_{i=1}^{r} \mathbf{A}_{i} \sigma_{i}^{2}+\mathbf{I} \sigma_{\varepsilon}^{2}
$$

where $\mathbf{y}$ is an $n \times 1$ vector of deregressed $E B V$, with $n$ being the sample size; $\mathbf{X}$ is an incidence matrix; $\boldsymbol{\beta}$ is a vector of fixed effects (only the intercept here); $\mathbf{g}_{i}$ denotes a vector of random effects attributable to the $i$ th of $r$ genetic factors, which could be the total genetic effect for the whole genome $(r=1)$ or for single chromosomes $(\mathrm{r}=30)$, respectively, with $\mathbf{g} \sim N\left(0, \mathbf{A}_{i} \sigma_{i}^{2}\right)$, where $\sigma_{i}^{2}$ and $\mathbf{A}_{i}$ represent the variance of the $i$ th genetic factor and the corresponding GRM, respectively; and $\varepsilon$ is a random residual term, with $\varepsilon \sim N\left(0, \mathbf{I} \sigma_{\varepsilon}^{2}\right)$, where $\sigma_{\varepsilon}^{2}$ represents the residual variance and $\mathbf{I}$ represents an identity matrix. Thus, the phenotypic variance is partitioned into the variance explained by each of the genetic factors and the residual variance (Yang et al., 2011). The approach was applied to each of the 5 analyzed DIM. Estimates obtained for individual chromosomes were normalized for the respective chromosome length in $\mathrm{Mb}$ (bovine genome build UMD3.1; http:// www.bovinegenome.org/cgi-bin/gbrowse/bovine_ UMD31/) and expressed as the proportion of explained phenotypic variance per $\mathrm{Mb}$ of chromosome length.

\section{RESULTS AND DISCUSSION}

\section{Repeatability and Heritability Estimates Across the First 180 DIM}

Repeatability ranged from 0.41 (DIM 45 and 46, respectively) to 0.56 (DIM 11; see Figure 1). The high repeatability estimates in early lactation suggest a precise measurement in the beginning of lactation. This is in contrast to the results reported by Veerkamp and Thompson (1999), Coffey et al. (2002), and Berry et al. (2007), who found a large residual variance for DMI in early lactation.

Heritability varied from 0.26 (DIM 121) to 0.37 (DIM 180) when estimated using the random regression model (see Figure 1). The moderate heritability estimates indicate that variation exists among cows for DMI and that genetic selection for this trait is possible. The range of the heritability estimates is in agreement with results from earlier studies, but the trajectory differs from those obtained in other studies, particularly with regard to the heritability estimates in early lactation. The high estimates in the beginning of lactation are not consistent with previous findings from Berry et al. (2007) and Spurlock et al. (2012), who reported an increase in heritability with DIM (up to DIM 183). According to our results, the best response to selection could be expected if DMI is measured in early lactation and around DIM 180. However, recording of DMI is costly and difficult to be implemented in practice. Therefore, strong interest exists in alternatives, such as marker-assisted selection. One option is to mea-

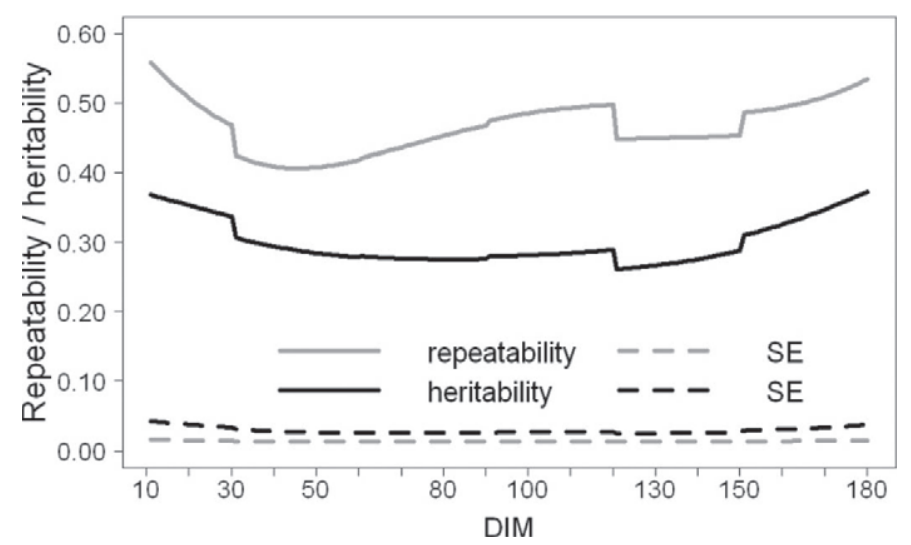

Figure 1. Estimated heritabilities and repeatabilities of DMI across the first 180 DIM. Lines represent daily estimates obtained from random regression analyses. 
Table 2. Heritability estimates (in bold) and genetic correlations between DMI observations at DIM 11, 30, 80, 130, and 180 (above the diagonal) obtained from random regression analyses, and phenotypic correlations

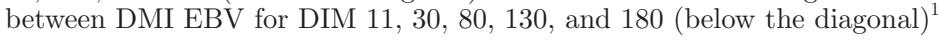

\begin{tabular}{|c|c|c|c|c|c|}
\hline \multirow[b]{2}{*}{ DIM } & \multicolumn{5}{|c|}{ DIM } \\
\hline & 11 & 30 & 80 & 130 & 180 \\
\hline 11 & $0.37(0.04)$ & $0.96(0.01)$ & $0.62(0.06)$ & $0.39(0.07)$ & $0.32(0.08)$ \\
\hline 30 & $0.97(0.01)$ & $0.34(0.03)$ & $0.81(0.03)$ & $0.60(0.05)$ & $0.41(0.07)$ \\
\hline 80 & $0.71(0.03)$ & $0.86(0.02)$ & $0.28(0.03)$ & $0.92(0.01)$ & $0.61(0.05)$ \\
\hline 130 & $0.47(0.03)$ & $0.63(0.03)$ & $0.91(0.02)$ & $0.27(0.03)$ & $0.84(0.03)$ \\
\hline 180 & $0.29(0.04)$ & $0.39(0.04)$ & $0.63(0.03)$ & $0.87(0.02)$ & $0.37(0.04)$ \\
\hline
\end{tabular}

${ }^{1}$ Corresponding SE in parentheses.

sure DMI in a subset of the Holstein population (e.g., within research herds consisting of cows that are both genotyped and phenotyped) to identify SNP associated with DMI and develop a SNP key that can be used to estimate genomic EBV for animals on commercial farms that have genotypes but no phenotypes (de Haas et al., 2012).

\section{Genetic Correlations Among Different DIM}

Genetic correlations between daily DMI observations at DIM 11, 30, 80, 130, and 180 were all positive, ranging from 0.29 (between DIM 11 and 180) to 0.97 (DIM 11 and 30; see Table 2). In contrast to previous estimates from the literature, all estimates obtained in the present study were significant $(P<0.05)$. The strength of the genetic correlation was inversely related to the time interval between compared DIM (Table 2). The results were generally in line with the findings of Veerkamp and Thompson (1999), Berry et al. (2007), and Hüttmann et al. (2009). Observations for DMI in mid lactation have a low predictive value with regard to early lactation DMI, and vice versa. Uncertainty remains about the genetic association between DMI in early and late lactation and mid and late lactation, respectively, as the present study was limited to the first 180 DIM. Nevertheless, our results show that DMI records from different DIM should be treated as separate traits. In a breeding program aiming to optimize overall feed efficiency of dairy cows over the entire lactation, repeated measurements of DMI in different stages of lactation would be needed (Liinamo et al., 2012).

Several authors have argued that genes influencing DMI might differ across stages of lactation (Coffey et al., 2001; Berry et al., 2007; Buttchereit et al., 2011; Liinamo et al., 2012). Therefore, a need exists to carefully consider stage of lactation when applying genomewide association studies for DMI. Actually, within the current study, no markers associated with DMI at more than 2 subsequent analyzed DIM were detected. The identification of genes that only have an effect on DMI during specific lactation stages may enable future selection to influence the DMI profile in a way that satisfies both the prevailing economic circumstances and welfare-related issues.

\section{GWAS}

The results of the GWAS are summarized in Table 3 and Figure 2. A total of 21 SNP on 10 chromosomes was found to be associated with DMI [Bonferroni $P$ $\left.\left(P_{\text {Bonf }}\right) \leq 0.1\right]$ for at least 1 DIM. Six of these markers were associated with DMI at 2 subsequent analyzed DIM. Thirteen of these 27 association signals showed chromosome-wise significance with $P_{\text {Bonf }} \leq 0.05$; no genome-wide significant associations were found. The quantile-quantile plots (Figure 2) indicate an adequate correction for relatedness among animals by using a mixed-model approach.

Although most chromosomes listed in Table 3 only harbor 1 or 2 associated SNP, 3, 4, and 5 associated SNP have been detected on BTA23, 25, and 17, respectively (Table 3 and Figure 2). The markers on BTA23 and 17 are spread across approximately 17 and approximately $40 \mathrm{Mb}$, respectively, and the affected lactation days range from DIM 30 to 180, indicating the presence of multiple QTL. This is also reflected by the large proportion of phenotypic variance explained by BTA17 across all analyzed lactation stages (Figure 3). Three of the associated markers on BTA23 are located within an interval $<3 \mathrm{Mb}$, thus likely reflecting the same QTL, whereas the fourth marker is located approximately 20 $\mathrm{Mb}$ apart (Table 3).

Previous QTL mapping and association studies considering DMI have predominantly been conducted in beef cattle. Within the public database AnimalQTLdb (http://www.animalgenome.org/cgi-bin/QTLdb/), 67 QTL for DMI spread across almost all cattle chromosomes are currently listed. These results were obtained in various breeds and by applying different methodologies naturally restricting the comparability to the current study in dairy cattle. However, 4 SNP found to be 
Table 3. Single nucleotide polymorphism markers associated with DMI

\begin{tabular}{|c|c|c|c|c|c|c|c|c|c|c|c|c|}
\hline \multirow[b]{3}{*}{ BTA } & \multirow[b]{3}{*}{ SNP ID ${ }^{1}$} & \multirow[b]{3}{*}{ Position $^{2}$} & \multicolumn{10}{|c|}{ DIM } \\
\hline & & & \multicolumn{2}{|r|}{11} & \multicolumn{2}{|r|}{30} & \multicolumn{2}{|r|}{80} & \multicolumn{2}{|c|}{130} & \multicolumn{2}{|r|}{180} \\
\hline & & & $P$-value ${ }^{3}$ & $\beta \pm \mathrm{SE}$ & $P$-value & $\beta \pm \mathrm{SE}$ & $P$-value & $\beta \pm \mathrm{SE}$ & $P$-value & $\beta \pm \mathrm{SE}$ & $P$-value & $\beta \pm \mathrm{SE}$ \\
\hline 13 & ARS-BFGL-NGS-118051 & $54,895,475$ & $7.38 \mathrm{E}-05^{*}$ & $-1.38 \pm 0.35$ & $1.02 \mathrm{E}-04^{*}$ & $-1.21 \pm 0.31$ & - & - & - & - & - & - \\
\hline 15 & BTB-00587441 & $25,693,584$ & - & - & - & - & $4.93 \mathrm{E}-05^{* *}$ & $1.00 \pm 0.25$ & - & - & - & - \\
\hline 16 & BTB-01533537 & $11,166,330$ & - & - & - & - & - & - & - & - & $1.30 \mathrm{E}-05^{* *}$ & $1.84 \pm 0.42$ \\
\hline \multirow[t]{5}{*}{17} & Hapmap33244-BTA-158544 & $30,904,465$ & - & - & - & - & - & - & - & - & $8.20 \mathrm{E}-05^{*}$ & $0.82 \pm 0.21$ \\
\hline & Hapmap38864-BTA-93656 & $48,048,314$ & - & - & - & - & - & - & - & - & $3.05 \mathrm{E}-05^{*}$ & $-0.97 \pm 0.23$ \\
\hline & $\begin{array}{l}\text { Hapmap33827-BES10_ } \\
\text { Contig357_1268 }\end{array}$ & $59,540,930$ & - & - & $7.84 \mathrm{E}-05^{*}$ & $0.73 \pm 0.19$ & - & - & - & - & - & - \\
\hline & ARS-BFGL-NGS-3221 & $63,255,304$ & - & - & - & - & - & - & $4.73 \mathrm{E}-05^{* *}$ & $-0.81 \pm 0.20$ & - & - \\
\hline & ARS-BFGL-BAC-35623 & $71,352,459$ & - & - & $1.10 \mathrm{E}-04^{*}$ & $-1.06 \pm 0.27$ & & & & & - & - \\
\hline \multirow[t]{3}{*}{23} & Hapmap57090-ss46526861 & $17,735,099$ & & & & & & & & & $1.11 \mathrm{E}-04 *$ & $0.81 \pm 0.21$ \\
\hline & UA-IFASA-8890 & $23,909,884$ & - & - & $7.86 \mathrm{E}-05^{* *}$ & $-0.69 \pm 0.18$ & $8.08 \mathrm{E}-05^{* *}$ & $-0.66 \pm 0.17$ & - & - & - & - \\
\hline & Hapmap50031-BTA-56452 & $35,816,005$ & - & - & $1.16 \mathrm{E}-04^{*}$ & $0.70 \pm 0.18$ & - & - & - & - & - & - \\
\hline \multirow[t]{4}{*}{25} & ARS-BFGL-NGS-102074 & $14,140,304$ & - & - & - & - & - & - & $9.20 \mathrm{E}-05^{* *}$ & $0.66 \pm 0.17$ & - & - \\
\hline & ARS-BFGL-NGS-115688 & $15,722,466$ & - & - & - & - & - & - & - & - & $1.52 \mathrm{E}-04^{*}$ & $-0.89 \pm 0.24$ \\
\hline & ARS-BFGL-NGS-90323 & $16,951,033$ & - & - & - & - & $1.34 \mathrm{E}-04 *$ & $0.79 \pm 0.21$ & - & - & - & - \\
\hline & Нарmap51005-BTA-60474 & $40,655,616$ & & & & & & & $1.51 \mathrm{E}-04 *$ & $0.69 \pm 0.18$ & & \\
\hline 27 & ARS-BFGL-NGS-63869 & $22,664,398$ & $9.76 \mathrm{E}-05^{* *}$ & $-1.60 \pm 0.41$ & $1.70 \mathrm{E}-04^{*}$ & $-1.39 \pm 0.37$ & - & - & - & - & - & - \\
\hline \multirow[t]{2}{*}{28} & ARS-BFGL-NGS-93286 & $3,105,798$ & - & - & $9.25 \mathrm{E}-05^{* *}$ & $0.91 \pm 0.23$ & - & - & - & - & - & - \\
\hline & BTB-00080204 & $16,412,210$ & $9.08 \mathrm{E}-05^{* *}$ & $-0.87 \pm 0.22$ & $6.06 \mathrm{E}-05^{* *}$ & $-0.80 \pm 0.20$ & - & - & - & - & - & - \\
\hline \multirow[t]{2}{*}{29} & UA-IFASA-4358 & $17,796,803$ & $1.46 \mathrm{E}-04^{*}$ & $0.74 \pm 0.20$ & - & - & - & - & - & - & - & - \\
\hline & ARS-BFGL-NGS-116911 & $25,487,607$ & - & - & - & - & - & - & $7.13 \mathrm{E}-05^{* *}$ & $-0.84 \pm 0.21$ & $5.12 \mathrm{E}-05^{* *}$ & $-1.03 \pm 0.25$ \\
\hline $\mathrm{X}$ & BTA-106988-no-rs & $118,434,643$ & - & - & - & - & - & - & $1.25 \mathrm{E}-04^{*}$ & $0.69 \pm 0.18$ & $8.55 \mathrm{E}-05^{* *}$ & $0.85 \pm 0.22$ \\
\hline
\end{tabular}

Genomic position in bp according to the cattle genome build UMD3.1 (http://www.bovinegenome.org/cgi-bin/gbrowse/bovine_UMD31/)

**Indicates chromosome-wise significance with a Bonferroni (simple $M$; Gao et al., 2008) corrected $P$-value $\leq 0.05$; *indicates marginal significance with a corrected $P$-value $\leq 0.1$. 


\section{A. Lactation day 11}

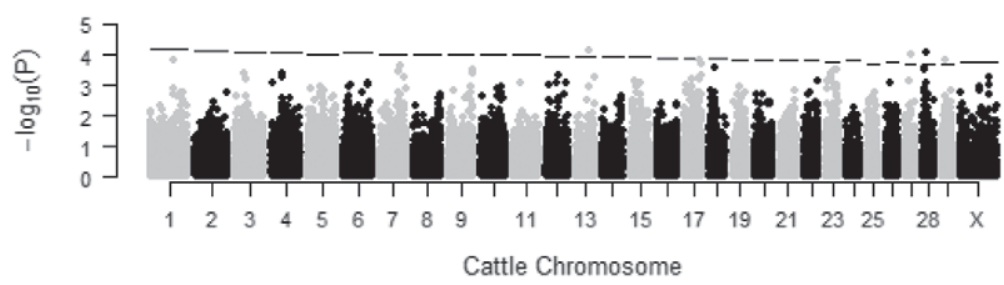

B. Lactation day 30

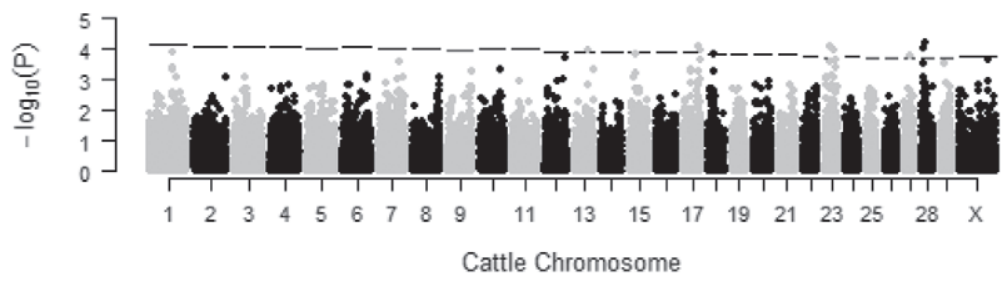

C. Lactation day 80

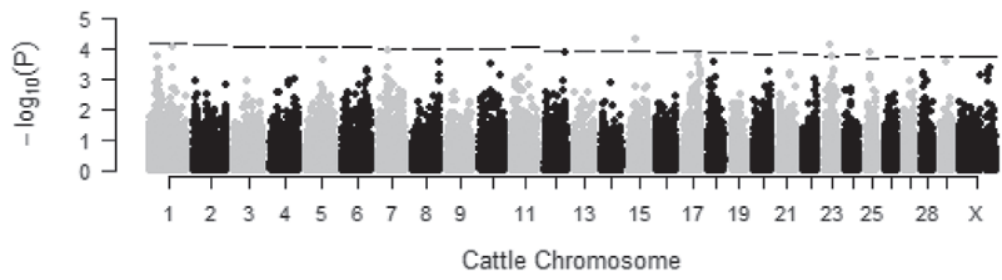

D. Lactation day 130

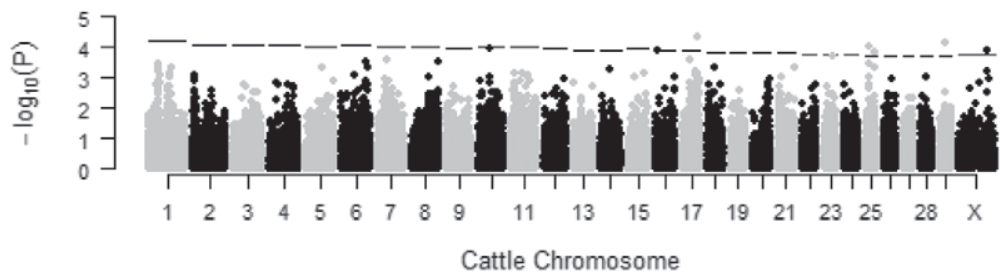

E. Lactation day 180

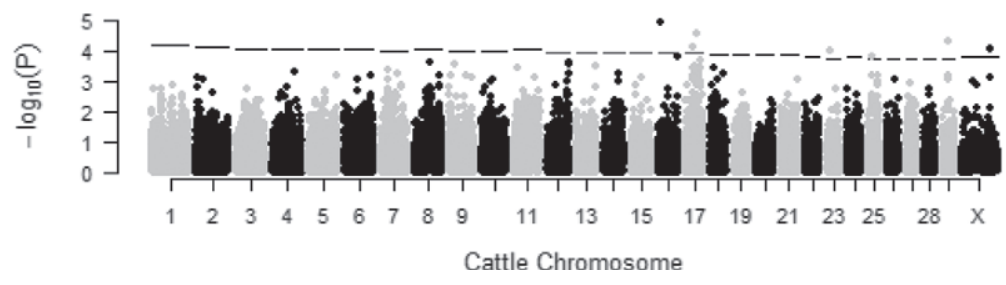

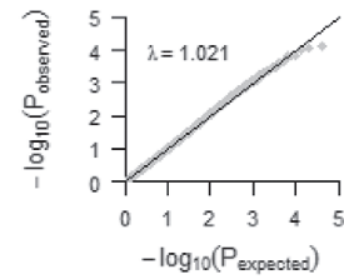
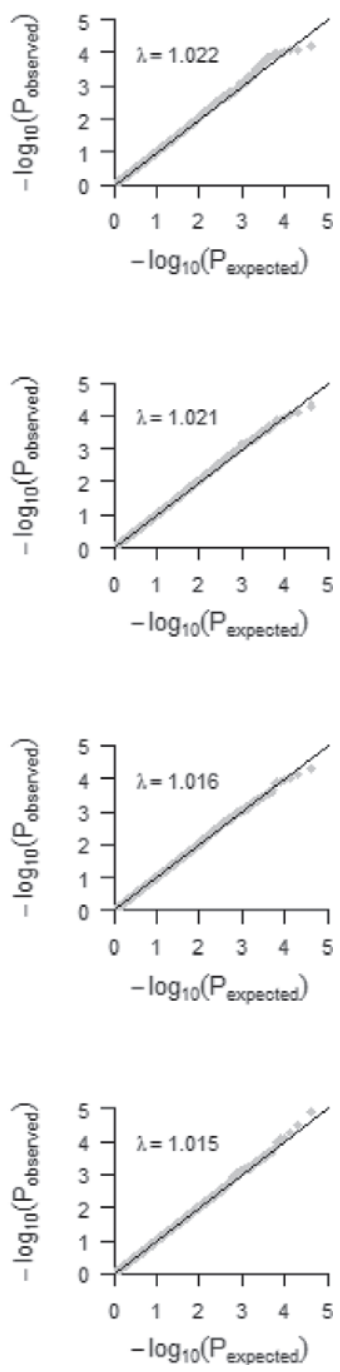

Figure 2. Results of the genome-wide association study for DMI. For each of the 5 analyzed lactation days, the negative decadic logarithms of the raw $P$-values are depicted in a Manhattan plot (left) and a quantile-quantile plot comparing the expected and observed distribution of $P$-values is given (right). Horizontal lines in the Manhattan plot indicate the Bonferroni-corrected (simple $M$; Gao et al., 2008) threshold for chromosome-wise significance at $P \leq 0.1$. $\lambda$ represents the genomic inflation factor (Devlin and Roeder, 1999).

associated with DMI in the current study are located within a maximum distance of $5 \mathrm{Mb}$ to 6 previously published QTL in beef cattle (Nkrumah et al., 2007; Márquez et al., 2009; Sherman et al., 2010; see Table 4 for details). A further 10 QTL on BTA13, 15, 16, 17, 23 , and 25 with a larger distance to the associated SNP listed in Table 2 have been reported in beef breeds (Nkrumah et al., 2007; Sherman et al., 2008, 2009, 2010; Márquez et al., 2009). The low concordance between previous results and the current report might simply be due to the fact that animals in different physiological states (i.e., growing and lactating) from completely 

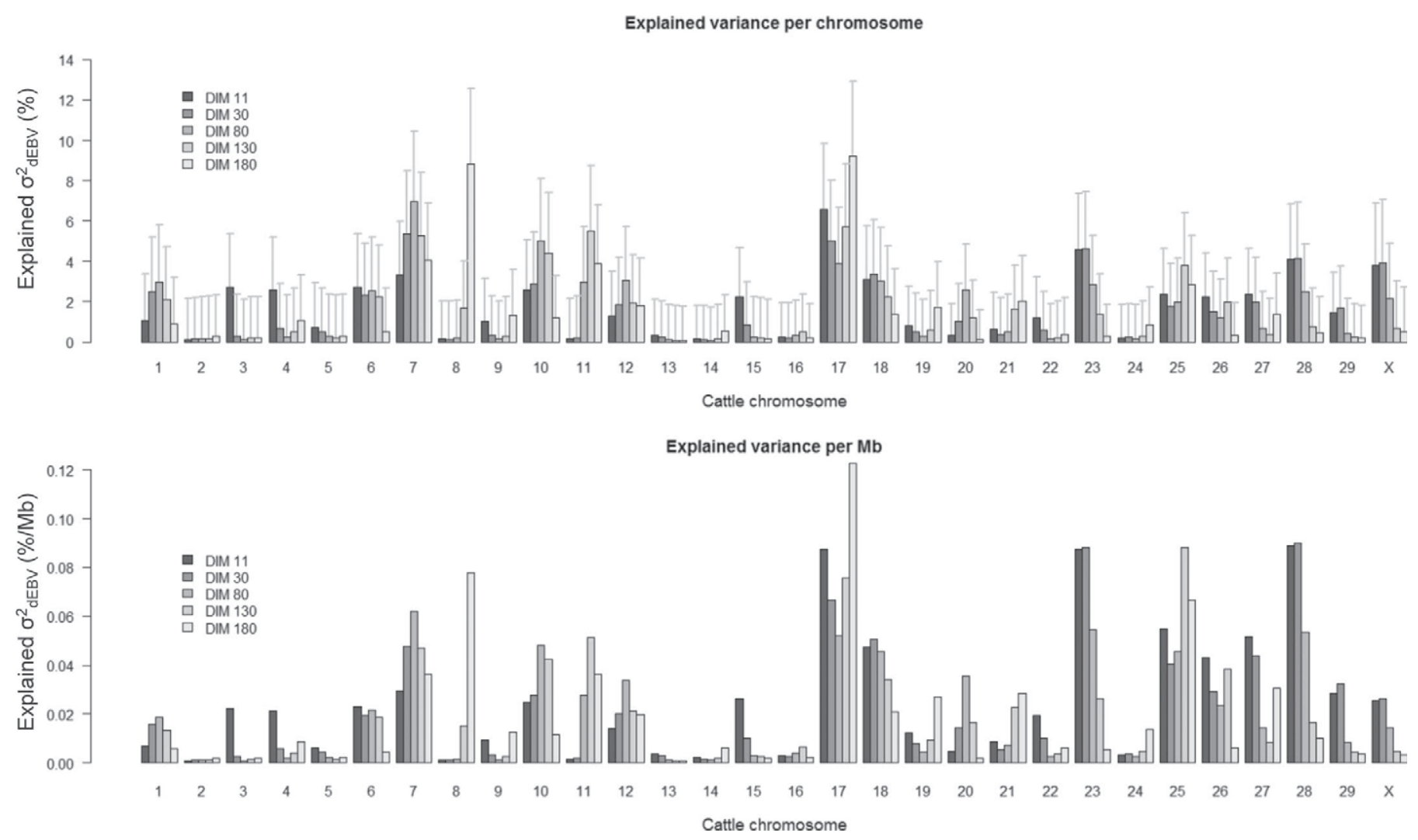

Figure 3. Estimates of deregressed EBV (dEBV) variance $\left(\sigma_{\mathrm{dEBV}}^{2}\right)$ explained by chromosomes. The upper part of the figure depicts the estimates in percentage of explained variance; error bars represent SE. The lower part of the figure shows the estimates corrected for chromosome length expressed as percentage of explained variance per Mb.

different breeds were analyzed, but also due to different phenotypes, which in other studies are based on DMI averaged over time. A higher concordance could be expected with results obtained from other Holstein populations, but such studies are scarce. Banos et al. (2008) analyzed 4 candidate genes and reported associations between DMI and SNP in the genes encoding the growth hormone receptor $(G H R)$ and leptin $(L E P)$ located on BTA20 and BTA4, respectively. Recently, Veerkamp et al. (2012) conducted a GWAS for DMI in Holstein cattle. These authors identified associations on 9 different cattle chromosomes, including BTA13 and 27 , which were also identified in the current study. However, the closest distance between association signals from the 2 studies was approximately $20 \mathrm{Mb}$. The discrepancies between this and the current GWAS might be explained by different phenotypes, which were averaged DMI for wk 3 to 15 of lactation in that study. Furthermore, a difference in statistical power exists, as Veerkamp et al. (2012) analyzed >1,600 cows, which is also reflected by the fact that we did not detect any genome-wide significant association. Dry matter intake might also directly affect energy balance and signifi- cantly positive genetic correlations of 0.73 have been reported for DIM 120 and 150 by Buttchereit et al. (2011). Based on that study, Tetens et al. (2013) used deregressed breeding values obtained from an extended data set in a GWAS for energy balance in early lactation. Within the current study, EBV were estimated in a further extended data set. However, no associated genome regions exist affecting energy balance and DMI simultaneously. For both traits, QTL were identified on BTA13, but they are $>30 \mathrm{Mb}$ apart. Results can hardly be compared, however, as only 2 DIM were analyzed in common and the current data set is larger than the previous one. Nevertheless, future joint analyses of energy balance and the main contributing factors, such as DMI and ECM yield, might provide insights into the mechanisms of early lactation energy metabolism.

\section{Candidate Genes}

The above-mentioned facts illustrate the complex nature of the phenotype DMI. Food intake and feeding behavior are subject to complex regulation, with many genes involved, each of them probably exhibiting only 
a small effect. Nevertheless, several regulating circuits are well known. The control of food intake is accomplished by peripheral regulators, such as adipose tissue hormones (e.g., leptin and adiponectin), pancreatic and gut hormones (e.g., ghrelin or cholecystokinin), and central regulators. The latter include specific hypothalamic structures, such as the arcuate nucleus and neuropeptides (e.g., neuropeptide $\mathrm{Y}$ and the melanocortin system). Furthermore, the reward system, including opioid, dopaminergic, and cannabinoid systems, plays a role in the regulation of appetite. For a review of the mechanisms known to be involved, see Stanley et al. (2005), Guyenet and Schwartz (2012), and Hussain and Bloom (2013). Despite the complexity, we looked for genes clearly known to be involved in the regulation of food intake in close vicinity of the associated SNP $( \pm 1 \mathrm{Mb})$ and identified a total of 9 functional candidate genes or clusters of genes (Table 5). Notably, close to the associated SNP ARS-BFGL-NGS-118051 on BTA13 (Table 3), 3 highly plausible candidate genes are found. Approximately $650 \mathrm{~kb}$ apart from the SNP, the gene encoding for the neuropeptide $\mathrm{B} / \mathrm{W}$ receptor 2 (NPBWR2) is located. Together with the neuropeptide $\mathrm{B} / \mathrm{W}$ receptor 1 and the endogenous peptide ligands neuropeptide B and W (NPB/NPW), it has been implicated in the regulation of food intake [reviewed by Sakurai (2013) and Takenoya et al. (2010)]. Especially the action of NPW has been analyzed and it has been proposed to be a key player in the hypothalamic regulation of food intake and energy metabolism (Takenoya et al., 2010). Adjacent to NPBWR2, the gene encoding for the opiate receptor-like 1 (OPRL1) is located. This $\mathrm{G}$ protein-coupled receptor binds the neuropeptide nociceptin and has been shown to stimulate food intake, regulate meal pattern, and inhibit the excitability of proopiomelanocortin, anorectic hypothalamic neuropeptide (POMC) neurons in the arcuate nucleus (Farhang et al., 2010). With a distance of approximately $220 \mathrm{~kb}$, even closer to the associated SNP, the gene encoding for the neurotensin receptor 1 (NTSR 1) is located. This receptor has been shown to mediate anorectic effects of neurotensin and neurotensin-related peptides (Kim and Mizuno, 2010).

On BTA28, a cluster of at least 23 olfactory receptor genes can be found in the vicinity of the associated SNP UA-IFASA-4358. Olfactory receptors might influence the individual palatability of feed and thus affect DMI, which was also stated by Veerkamp et al. (2012).

\section{Variance Explained by Markers}

The deregressed EBV variances explained by all typed markers, also referred to as chip heritability, were estimated to be 0.45 for DIM 11; 0.39 for DIM 30, 50,

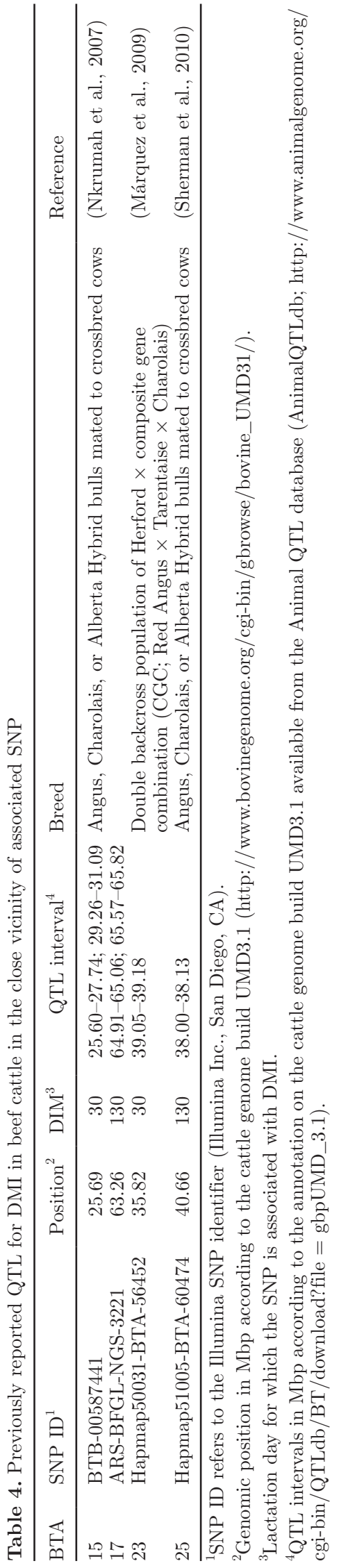




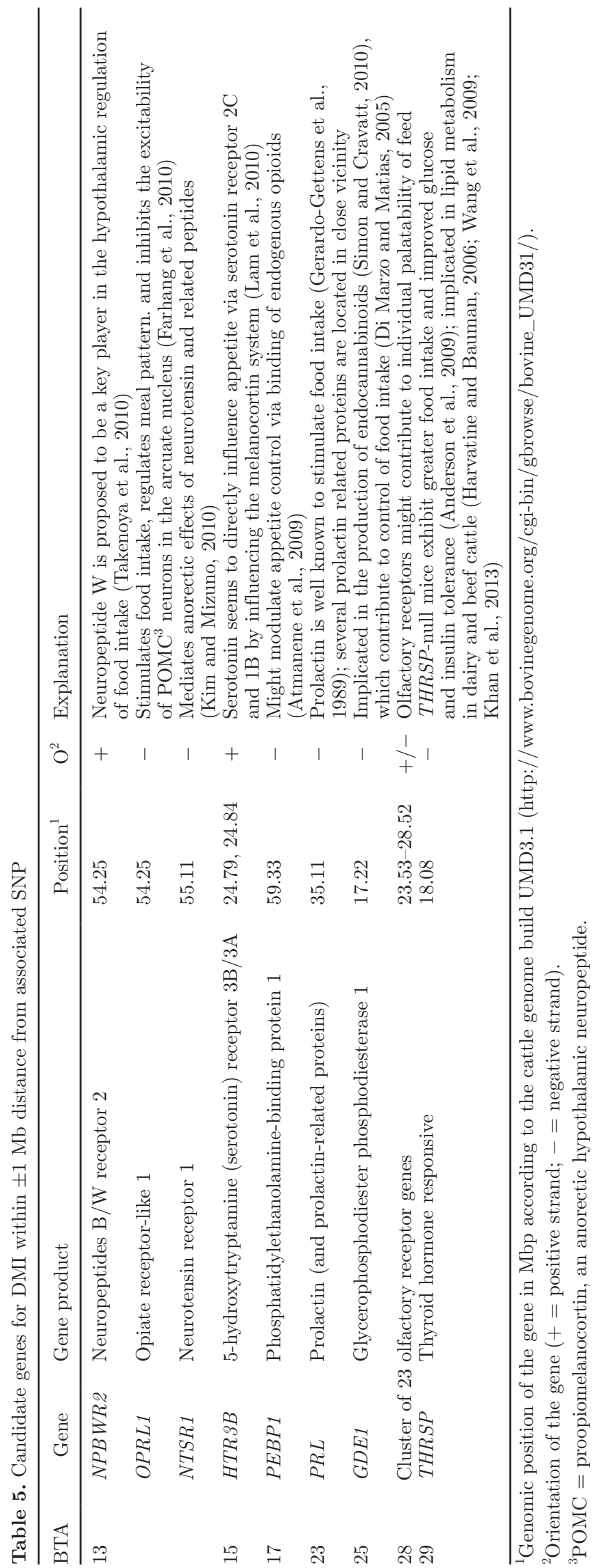

and 130; and 0.38 for DIM 180; the standard errors were approximately 0.08 for all estimates. The trajectory across lactation days is in general concordance with the heritability estimates given in Table 2, but as deregressed EBV were used as phenotypes, the chip heritability estimates were larger except for DIM 180.

The results obtained from partitioning the variance onto chromosomes are summarized in Figure 3. The estimates are generally afflicted with high standard errors, as shown in the upper part of Figure 3, but for the larger estimates as, for example, obtained for BTA7 and 17, approximate 90\% confidence intervals do not include zero. The mean proportion of explained deregressed EBV variance explained per chromosome ranges from 1.55 to $1.84 \%$ for DIM 130 and 11 (upper part of Figure 3), respectively, whereas the mean length corrected values (lower part of Figure 3) range from $0.02 \% / \mathrm{Mb}$ (DIM 80, 130, and 180 ) to $0.025 \% / \mathrm{Mb}$ (DIM 11).

Bos taurus autosome 17 consistently explains a large proportion of variance across lactation stages, ranging from 3.9 to $9.2 \%$ for DIM 80 and 180, respectively. After correction for chromosome length, BTA17 also provides the highest value of $0.12 \%$ of explained variance per megabase pair at DIM 180 (lower part of Figure 3). These findings are in accordance with the results of the BWAS, as BTA17 harbors the highest number of associated SNP spread across a large proportion of the chromosome (Table 3 ). Bos taurus autosome 23 and BTA28 explain a relatively large proportion of the variance in early lactation. As these chromosomes are among the shorter ones, this becomes even more pronounced when correcting for length. These findings are also in agreement with the GWAS and for BTA23 possibly reflect the comparatively high density of approximately 18 genes/Mb (mean across genome: $\sim 10$ genes/Mb) annotated on this chromosome (calculated based on the current annotation of genome build UMD3.1; http:// www.ncbi.nlm.nih.gov/genome/genomes/82?details = on\&project_id $=33843$ ). The BTAX explains a similar proportion of variance in early lactation, but as for this comparatively large chromosome, the length-corrected values are close to the mean. The estimates of explained variance are not in concordance with the results of the GWAS for BTA7 and BTA8. The latter explains a high proportion of variance for DIM 180, whereas BTA7 explains a high amount around DIM 80, but no associated SNP have been detected. Several QTL have previously been reported at various locations across both chromosomes (Nkrumah et al., 2007; Sherman et al., 2009, 2010; Veerkamp et al., 2012). The contribution of these chromosomes might be due to several QTL with small effects not detectable with the power achieved in the current study. 


\section{CONCLUSIONS}

Selection for DMI has to be seen in the context of conflictive requirements regarding animal health and efficiency. One option for a sustainable approach is to appropriately remodel the trajectory of DMI across lactation to meet both requirements. Within the current study, it was shown that genetic regulation of DMI differed between early and mid lactation and that genetic correlations between early and mid lactation were lower than those observed for milk yield traits. The results of a sequential GWAS for 5 different DIM supported these findings and pointed at some interesting lactation stage-specific candidate genes and pathways. However, the study was limited to first lactation, with emphasis on the first 180 DIM. Future studies may also consider multiple lactations and later lactation stages. Also, sample size should be enlarged. Recently, partners from 9 different countries (Australia, Canada, Denmark, Germany, Ireland, New Zealand, the Netherlands, United Kingdom, and United States) have pooled data on DMI and associated genotypes across countries within the framework of the project global Dry Matter Initiative (gDMI). Merging of experimental data will increase the power of detection in GWAS and open the way for the estimation of genomic EBV for DMI, thereby enabling an incorporation of this trait into national breeding programs (Banos et al., 2012; de Haas et al., 2012). The present study was designed to gain a better understanding of the complex nature of the phenotype DMI. Some gaps in knowledge have been closed, but future studies on genetic correlations between DMI and other important traits are necessary to tackle the above-mentioned tasks.

\section{ACKNOWLEDGMENTS}

We gratefully acknowledge financial support from the German Federal Ministry of Education and Research (Berlin, Germany; project FUGATO-plus GENOTRACK, grant no. 0315134A), from the KMSH (Kompetenzzentrum Milch - Schleswig-Holstein, Kiel, Germany), and from the NOG Nord-Ost Genetic GmbH \& Co. KG (Verden, Germany). We are grateful to Wolfgang Junge (Institute of Animal Breeding and Husbandry, Kiel University, Kiel, Germany) and Eckhard Stamer (TiDa Tier und Daten GmbH, Westensee/ Brux, Germany) as well as the Karkendamm research farm staff for their efforts.

\section{REFERENCES}

Ali, T. E., and L. R. Schaeffer. 1987. Accounting for covariances among test day milk yields in dairy cows. Can. J. Anim. Sci. 67:637-644.

Anderson, G. W., Q. Zhu, J. Metkowski, M. J. Stack, S. Gopinath, and C. N. Mariash. 2009. The Thrsp null mouse (Thrsp ${ }^{\text {tm } 1 c n m}$ ) and diet-induced obesity. Mol. Cell. Endocrinol. 302:99-107.
Atmanene, C. d., A. Laux, E. Glattard, A. Muller, F. Schoentgen, M.-H. Metz-Boutigue, D. Aunis, A. Van Dorsselaer, G. B. Stefano, S. Sanglier-Cianférani, and Y. Goumon. 2009. Characterization of human and bovine phosphatidylethanolamine-binding protein (PEBP/RKIP) interactions with morphine and morphine-glucuronides determined by noncovalent mass spectrometry. Med. Sci. Monit. 15:BR178-BR187.

Banos, G., M. P. Coffey, R. F. Veerkamp, D. P. Berry, and E. Wall. 2012. Merging and characterising phenotypic data on conventional and rare traits from dairy cattle experimental resources in three countries. Animal 6:1040-1048.

Banos, G., J. A. Woolliams, B. W. Woodward, A. B. Forbes, and M. P. Coffey. 2008. Impact of single nucleotide polymorphisms in leptin, leptin receptor, growth hormone receptor, and diacylglycerol acyltransferase (DGAT1) gene loci on milk production, feed, and body energy traits of UK dairy cows. J. Dairy Sci. 91:3190-3200.

Berry, D. P., and J. J. Crowley. 2013. Cell Biology Symposium: Genetics of feed efficiency in dairy and beef cattle. J. Anim. Sci. 91:1594-1613.

Berry, D. P., B. Horan, M. O’Donovan, F. Buckley, E. Kennedy, M. McEvoy, and P. Dillon. 2007. Genetics of grass dry matter intake, energy balance, and digestibility in grazing Irish dairy cows. J. Dairy Sci. 90:4835-4845.

Buttchereit, N., E. Stamer, W. Junge, and G. Thaller. 2011. Short communication: Genetic relationships among daily energy balance, feed intake, body condition score, and fat to protein ratio of milk in dairy cows. J. Dairy Sci. 94:1586-1591.

Coffey, M. P., G. C. Emmans, and S. Brotherstone. 2001. Genetic evaluation of dairy bulls for energy balance traits using random regression. Anim. Sci. 73:29-40.

Coffey, M. P., G. Simm, and S. Brotherstone. 2002. Energy balance profiles for the first three lactations of dairy cows estimated using random regression models. J. Dairy Sci. 85:2669-2678.

Collard, B. L., P. J. Boettcher, J. C. M. Dekkers, D. Petitclerc, and L. R. Schaeffer. 2000. Relationships between energy balance and health traits of dairy cattle in early lactation. J. Dairy Sci. 83:2683-2690.

de Haas, Y., M. P. L. Calus, R. F. Veerkamp, E. Wall, M. P. Coffey, H. D. Daetwyler, B. J. Hayes, and J. E. Pryce. 2012. Improved accuracy of genomic prediction for dry matter intake of dairy cattle from combined European and Australian data sets. J. Dairy Sci. 95:6103-6112.

Devlin, B., and K. Roeder. 1999. Genomic control for association studies. Biometrics 55:997-1004.

Di Marzo, V., and I. Matias. 2005. Endocannabinoid control of food intake and energy balance. Nat. Neurosci. 8:585-589.

Farhang, B., L. Pietruszewski, K. Lutfy, and E. J. Wagner. 2010. The role of the NOP receptor in regulating food intake, meal pattern, and the excitability of proopiomelanocortin neurons. Neuropharmacology 59:190-200.

Fischer, T. M., A. R. Gilmour, and J. H. J. van der Werf. 2004. Computing approximate standard errors for genetic parameters derived from random regression models fitted by average information REML. Genet. Sel. Evol. 36:363-369.

Gao, X., L. C. Becker, D. M. Becker, J. D. Starmer, and M. A. Province. 2010. Avoiding the high Bonferroni penalty in genome-wide association studies. Genet. Epidemiol. 34:100-105.

Gao, X., J. Starmer, and E. R. Martin. 2008. A multiple testing correction method for genetic association studies using correlated single nucleotide polymorphisms. Genet. Epidemiol. 32:361-369.

Gerardo-Gettens, T., B. J. Moore, J. S. Stern, and B. A. Horwitz. 1989. Prolactin stimulates food intake in a dose-dependent manner. Am. J. Physiol. 256:R276-R280.

Gilmour, A. R., B. J. Gogel, B. R. Cullis, and R. Thompson. 2009. ASReml User Guide. Release 3.0. VSN International Ltd., Hemel Hempstead, UK.

Goff, J. P., and R. L. Horst. 1997. Physiological changes at parturition and their relationship to metabolic disorders. J. Dairy Sci. 80:1260-1268.

Guyenet, S. J., and M. W. Schwartz. 2012. Regulation of food intake, energy balance, and body fat mass: Implications for the patho- 
genesis and treatment of obesity. J. Clin. Endocrinol. Metab. $97: 745-755$.

Harvatine, K. J., and D. E. Bauman. 2006. SREBP1 and thyroid hormone responsive spot 14 (S14) are involved in the regulation of bovine mammary lipid synthesis during diet-induced milk fat depression and treatment with CLA. J. Nutr. 136:2468-2474.

Heringstad, B., G. Klemetsdal, and J. Ruane. 2000. Selection for mastitis resistance in dairy cattle: A review with focus on the situation in the Nordic countries. Livest. Prod. Sci. 64:95-106.

Hussain, S. S., and S. R. Bloom. 2013. The regulation of food intake by the gut-brain axis: Implications for obesity. Int. J. Obes. (Lond.) 37:625-633.

Hüttmann, H., E. Stamer, W. Junge, G. Thaller, and E. Kalm. 2009. Analysis of feed intake and energy balance of high-yielding first lactating Holstein cows with fixed and random regression models. Animal 3:181-188.

Khan, M. J., A. Hosseini, S. Burrell, S. M. Rocco, J. P. McNamara, and J. J. Loor. 2013. Change in subcutaneous adipose tissue metabolism and gene network expression during the transition period in dairy cows, including differences due to sire genetic merit. J. Dairy Sci. 96:2171-2182.

Kim, E. R., and T. M. Mizuno. 2010. Role of neurotensin receptor 1 in the regulation of food intake by neuromedins and neuromedinrelated peptides. Neurosci. Lett. 468:64-67.

Koenen, E. P. C., and R. F. Veerkamp. 1998. Genetic covariance functions for live weight, condition score, and dry-matter intake measured at different lactation stages of Holstein Friesian heifers. Livest. Prod. Sci. 57:67-77.

Lam, D. D., A. S. Garfield, O. J. Marston, J. Shaw, and L. K. Heisler. 2010. Brain serotonin system in the coordination of food intake and body weight. Pharmacol. Biochem. Behav. 97:84-91.

Liinamo, A.-E., P. Mäntysaari, and E. A. Mäntysaari. 2012. Short communication: Genetic parameters for feed intake, production, and extent of negative energy balance in Nordic Red dairy cattle. J. Dairy Sci. 95:6788-6794.

Márquez, G. C., R. M. Enns, M. D. Grosz, L. J. Alexander, and M. D. MacNeil. 2009. Quantitative trait loci with effects on feed efficiency traits in Hereford $\times$ composite double backcross populations. Anim. Genet. 40:986-988.

Nkrumah, J. D., E. L. Sherman, C. Li, E. Marques, D. H. Crews, R. Bartusiak, B. Murdoch, Z. Wang, J. A. Basarab, and S. S. Moore. 2007. Primary genome scan to identify putative quantitative trait loci for feedlot growth rate, feed intake, and feed efficiency of beef cattle. J. Anim. Sci. 85:3170-3181.

Pryce, J. E., and P. Løvendahl. 1999. Options to reduce vulnerability to metabolic stress by genetic selection. Pages 119-127 in Metabolic Stress in Dairy Cows. J. D. Oldham, G. Simm, A. F. Groen, B. L. Nielsen, J. E. Pryce, and T. L. J. Lawrence, ed. Occasional Publication No. 24. British Society of Animal Science, Penicuik, UK.

Purcell, S., B. Neale, K. Todd-Brown, L. Thomas, M. A. R. Ferreira, D. Bender, J. Maller, P. Sklar, P. I. W. de Bakker, M. J. Daly, and P. C. Sham. 2007. PLINK: A tool set for whole-genome association and population-based linkage analyses. Am. J. Hum. Genet. 81:559-575.

Reist, M., D. K. Erdin, D. von Euw, K. M. Tschümperlin, H. Leuenberger, H. M. Hammon, C. Morel, C. Philipona, Y. Zbinden, N. Künzi, and J. W. Blum. 2003. Postpartum reproductive function: Association with energy, metabolic and endocrine status in high yielding dairy cows. Theriogenology 59:1707-1723.
Sakurai, T. 2013. NPBWR1 and NPBWR2: Implications in energy homeostasis, pain, and emotion. Front. Endocrinol. (Lausanne) $4: 23$.

Sherman, E. L., J. D. Nkrumah, C. Li, R. Bartusiak, B. Murdoch, and S. S. Moore. 2009. Fine mapping quantitative trait loci for feed intake and feed efficiency in beef cattle. J. Anim. Sci. 87:37-45.

Sherman, E. L., J. D. Nkrumah, and S. S. Moore. 2010. Whole genome single nucleotide polymorphism associations with feed intake and feed efficiency in beef cattle. J. Anim. Sci. 88:16-22.

Sherman, E. L., J. D. Nkrumah, B. M. Murdoch, C. Li, Z. Wang, A. $\mathrm{Fu}$, and S. S. Moore. 2008. Polymorphisms and haplotypes in the bovine neuropeptide $\mathrm{Y}$, growth hormone receptor, ghrelin, insulinlike growth factor 2 , and uncoupling proteins 2 and 3 genes and their associations with measures of growth, performance, feed efficiency, and carcass merit in beef cattle. J. Anim. Sci. 86:1-16.

Simon, G. M., and B. F. Cravatt. 2010. Characterization of mice lacking candidate $\mathrm{N}$-acyl ethanolamine biosynthetic enzymes provides evidence for multiple pathways that contribute to endocannabinoid production in vivo. Mol. Biosyst. 6:1411-1418.

Spurlock, D. M., J. C. M. Dekkers, R. Fernando, D. A. Koltes, and A. Wolc. 2012. Genetic parameters for energy balance, feed efficiency, and related traits in Holstein cattle. J. Dairy Sci. 95:5393-5402.

Stanley, S., K. Wynne, B. McGowan, and S. Bloom. 2005. Hormonal regulation of food intake. Physiol. Rev. 85:1131-1158.

Takenoya, F., H. Kageyama, K. Shiba, Y. Date, M. Nakazato, and S. Shioda. 2010. Neuropeptide W: A key player in the homeostatic regulation of feeding and energy metabolism? Ann. N. Y. Acad. Sci. 1200:162-169.

Tetens, J., T. Seidenspinner, N. Buttchereit, and G. Thaller. 2013. Whole-genome association study for energy balance and fat/protein ratio in German Holstein bull dams. Anim. Genet. 44:1-8.

Vallimont, J. E., C. D. Dechow, J. M. Daubert, M. W. Dekleva, J. W. Blum, C. M. Barlieb, W. Liu, G. A. Varga, A. J. Heinrichs, and C. R. Baumrucker. 2010. Genetic parameters of feed intake, production, body weight, body condition score, and selected type traits of Holstein cows in commercial tie-stall barns. J. Dairy Sci. 93:4892-4901.

Van Arendonk, J. A. M., G. J. Nieuwhof, H. Vos, and S. Korver. 1991. Genetic aspects of feed intake and efficiency in lactating dairy heifers. Livest. Prod. Sci. 29:263-275.

Veerkamp, R. F. 1998. Selection for economic efficiency of dairy cattle using information on live weight and feed intake: A review. J. Dairy Sci. 81:1109-1119.

Veerkamp, R. F., M. P. Coffey, D. P. Berry, Y. de Haas, E. Strandberg, H. Bovenhuis, M. P. L. Calus, and E. Wall. 2012. Genome-wide associations for feed utilization complex in primiparous HolsteinFriesian dairy cows from experimental research herds in four European countries. Animal 6:1738-1749.

Veerkamp, R. F., and R. Thompson. 1999. A covariance function for feed intake, live weight, and milk yield estimated using a random regression model. J. Dairy Sci. 82:1565-1573.

Wang, Y. H., N. I. Bower, A. Reverter, S. H. Tan, N. De Jager, R. Wang, S. M. McWilliam, L. M. Cafe, P. L. Greenwood, and S. A. Lehnert. 2009. Gene expression patterns during intramuscular fat development in cattle. J. Anim. Sci. 87:119-130.

Yang, J., S. H. Lee, M. E. Goddard, and P. M. Visscher. 2011. GCTA: A tool for genome-wide complex trait analysis. Am. J. Hum. Genet. 88:76-82.

Zhou, X., and M. Stephens. 2012. Genome-wide efficient mixed-model analysis for association studies. Nat. Genet. 44:821-824. 